EL DINAR: Jurnal Keuangan dan Perbankan Syariah

Volume 6 , No. 1, Tahun 2018

P ISSN: 2339-2797; E ISSN: 2622-0083

\title{
MEWUJUDKAN LEMBAGA KEUANGAN MIKRO SYARIAH BERBASIS LABORATORIUM
}

\author{
Esy Nur Aisyah \\ Universitas Islam Negeri Maulana Malik Ibrahim Malang \\ esynuraisyah@yahoo.com \\ Siswanto \\ Universitas Islam Negeri Maulana Malik Ibrahim Malang \\ siswanto@pbs.uin-malang.ac.id \\ Yayuk Sri Rahayu \\ Universitas Islam Negeri Maulana Malik Ibrahim Malang \\ yayukfeuinmalang@gmail.com
}

\section{Abstract}

Educational institutions have a challenge to improve the quality of graduates who are highly competitive namely graduates who are able to adapt quickly to the work environment. This is a key indicator of the "links and match" between human resources need and education laboratories. The role of the real laboratory is very important to be used as a learning resource for Islamic banks as well as a medium of socialization or education within the scope of the academic community. This paper seeks to provide an overview based on the author's experience to realize or establish a real transaction laboratory for Eldinar Finance House, starting from the pioneering stage to the technical implementation which is synergized with the student learning model.

Key words: Human Resource; Islamic Banking Laboratory; Source and Learning Model

\section{Abstrak}

Lembaga pendidikan memiliki tantangan untuk meningkatkan kualitas lulusan yang berdaya saing tinggi. Yakni, lulusan yang mampu beradaptasi secara cepat terhadap lingkungan kerja sebagai indikator utama tercapainya link and match kebutuhan Sumber Daya Insani di industri dengan laboratorium pendidikan. Peran Laboratorium riil menjadi sangat penting untuk djadikan sumber pembelajaran bank syariah sekaligus media sosialisasi atau edukasi dalam lingkup civitas akademika. Tulisan ini berupaya untuk memberikan suatu gambaran berdasar pengalaman penulis untuk mewujudkan atau mendirikan laboratorium transaksi riil El-dinar Finance House, dimulai dari tahapan perintisan sampai dengan teknis pelaksanaan yang disinergikan dengan model pembelajaran mahasiswa. 
Esy Nur Aisyah: Mewujudkan Lembaga Keuangan Mikro Syariah

Kata kunci: Sumber Daya Insani; Laboratorium Perbankan Syariah; Sumber dan Model Pembelajaran

\section{PENDAHULUAN}

Lembaga pendidikan memiliki tantangan untuk meningkatkan kualitas lulusan yang berdaya saing tinggi. Yakni, lulusan yang mampu beradaptasi secara cepat terhadap lingkungan kerja sebagai indikator utama tercapainya link and match kebutuhan Sumber Daya Insani di industri dengan laboratorium pendidikan. Tantangan ini juga dihadapi jurusan perbankan syariah yang berada di Fakultas Ekonomi (FE) UIN Maulana Malik Ibrahim (Maliki) Malang. Jurusan perbankan syariah FE UIN Maliki telah memiliki kurikulum yang merupakan refleksi kebutuhan stakeholders dan laboratorium perbankan syariah sebagai media praktik mahasiswa. Namun, hal itu masih perlu dioptimalkan, terutama dalam hal mewujudkan lembaga keuangan mikro syariah sebagai laboratorium transaksi riil guna tercapainya link and match kebutuhan Sumber Daya Insani lembaga keuangan syariah yang berdaya saing tinggi sesuai dengan visi jurusan.

Hal ini merupakan peluang yang sangat prospektif, sekaligus merupakan tantangan bagi kalangan akademisi dan dunia pendidikan untuk menyiapkan Sumber Daya Insani (SDI) yang berkualitas yang ahli di bidang ekonomi syari'ah, bukan karbitan seperti yang banyak terjadi selama ini. Tingginya kebutuhan SDI bank syari'ah dan lembaga keuangan syariah ini menunjukkan bahwa sistem ekonomi syariah semakin dibutuhkan oleh masyarakat.

Untuk melahirkan SDI yang berkompeten di bidang ekonomi, bisnis dan hukum ekonomi syari'ah secara komprehensif dan memadai, serta memiliki integritas tinggi, maka dibutuhkan lembaga pendidikan ekonomi syari'ah yang secara khusus menyiapkan SDI ekonomi syari'ah. (SDI) ekonomi syari'ah,tidak boleh lagi bersifat bukan karbitan seperti yang banyak terjadi selama ini.

Sementara itu, lembaga pendidikan ekonomi keuangan syariah pada umumnya menghadapi sejumlah kendala dalam upaya mengembangkan kualitas. Kendala itu antara lain: (1) keterbatasan ahli ekonomi keuangan syariah, yang menguasai secara komprehensif ilmu 
Esy Nur Aisyah: Mewujudkan Lembaga Keuangan Mikro Syariah

ekonomi, keuangan sekaligus ilmu syariah, (2) keterbatasan dari segi kurikulum pengajaran, kurikulum belum berbasis kepada kompetensi, (3) belum ada linkage antara lembaga pendidikan dengan lembaga keuangan Syariah, dan (4) keterbatasan dana dan SDM sehingga research dan laboratorium penelitian di bidang ilmu ekonomi dan keuangan syariah masih terbatas (Agustianto, 2015).

Untuk melahirkan SDI yang berkompeten di bidang bisnis dan hukum syari'ah secara komprehensif dan memadai, serta memiliki integritas tinggi, maka dibutuhkan lembaga pendidikan ekonomi syari'ah yang secara khusus menyiapkan SDI ekonomi syari'ah. Karena itu perlu adanya redesign tentang institusi kependidikan di Indonesia terutama di Fakultas Ekonomi dan syariah, agar dapat dihasilkan sarjana yang mempunyai skills tentang ekonomi syari'ah dan memiliki budi pekerti yang sesuai dengan syariah Islam dan applicable di sektor ekonomi.

Dalam pengembangan pendidikan ekonomi keuangan syariah di Jurusan Perbankan syariah Fakultas ekonomi, penelitian ini lebih terfokus pada laboratorium transaksi riil lembaga keuangan mikro syariah sebagai sarana dan fasilitas belajar mahasiswa serta dapat menjadi wadah bagi mereka untuk melakukan pemagangan ataupun onjob training.

Kelebihan penyelenggaraan pembelajaran praktik secara riil adalah mahasiswa dituntut untuk dapat mengelola operasional bank syariah mulai dari upaya penggalangan dana tabungan, melakukan pendekatan kepada nasabah dengan bertindak sebagai marketer funding, menjelaskan sambil melaksanakan sosialisasi kepada masyarakat (atau civitas akademika) tentang prinsip kerja bank syariah, pola bagi hasil, pelaksanaan akad serta bagaimana mampu mengelola likuiditas secara baik sampai dengan mengelola aktiva pembiayaan sehingga kualitas akan selalu terjaga.

\section{KAJIAN PUSTAKA}

\section{Penelitian Terdahulu}

Pengembangan perbankan syariah di Indonesia menghadapi permasalahan ketersediaan Sumber Daya Insani (SDI). Permasalahan 
Esy Nur Aisyah: Mewujudkan Lembaga Keuangan Mikro Syariah

ketersediaan dan kebutuhan SDI tersebut tidak hanya dari segi kuantitas namun juga dari sisi kualitasnya. Hamzah (2008) menyatakan praktisi perbankan syariah didominasi kaum muhajirin konvensional, sehingga secara psikologis para praktisi perbankan syariah tersebut masih dalam tahap bagaimana mereka mampu menerapkan dan belum sampai pada tahap bagaimana mereka mampu mengembangkan. Adapun secara kualitas, SDI perbankan syariah Malaysia lebih baik dibandingkan SDI perbankan syariah di Indonesia. Ascarya dan Yusmanita (2008) menunjukkan kualitas SDI perbankan syariah di Indonesia berada dibawah SDI perbankan syariah di Malaysia. Sedangkan, kualitas SDI perbankan syariah yang tinggi menentukan efektivitas pengembangan industri keuangan syariah. Berdasarkan pandangan ini, maka diperlukan suatu lembaga yang dapat mewadahi kalangan praktisi dan akademisi untuk menyiapkan SDI yang berkualitas dan mampu beradaptasi secara cepat.

Zuhroh (2012) Laboratorium Bank Syariah merupakan sarana penopang pelaksanaan program Tri Dharma Perguruan Tinggi yang diharapkan mampu memberikan kontribusi turut mengakselerasi perkembangan syariah di Indonesia, maupun dapat berfungsi sebagai unit produksi Prodi ataupun Fakultas Ekonomi. Hasil dari pelaksanaan praktek di Laboratorium, demikian pula intensitas transaksi yang bakal berlangsung sangat ditentukan oleh oleh beberapa hal seperti: dukungan kebijakan pimpinan institusi khususnya dalam lingkup prodi dan Fakultas. Kebijakan dalam penyusunan kurikulum yang mendukung pelaksanaan praktek sangat diperlukan, dan tak kalah pentingnya adalah sistem dan model pembelajaran yang diberlakukan.

\section{Laboratorium}

Konsorsium Ilmu Pendidikan (1978) dalam Muhammad Amien (1988) definisi operasional laboratorium adalah prasarana, sarana dan mekanisme kerja yang menunjang secara unit satu atau lebih dari dharma sekolah dan atau madrasah (pendidikan dan pengajaran, penelitian serta pengabdian kepada masyarakat) melalui pengalaman langsung dalam membentuk keterampilan, pengembangan ilmu dan tekhnologi, serta pengabdian kepada masyarakat luas. 
Esy Nur Aisyah: Mewujudkan Lembaga Keuangan Mikro Syariah

Laboratorium merupakan salah satu sarana pendukung penting, yang bersifat sangat strategis dalam kegiatan pelaksanaan sistem pendidikan, khususnya pada sistem pendidikan di perguruan tinggi. Laboratorium pendidikan (khususnya pada perguruan tinggi), adalah unit penunjang akademik pada perguruan tinggi, yang digunakan untuk melaksanakan kegiatan pendidikan, penelitian, dan pengabdian kepada masyarakat; dengan menggunakan 1) peralatan dan 2) bahan, 3) berdasar metode keilmuan tertentu.

1. Peralatan Laboratorium

Peralatan Laboratorium Adalah mesin, perkakas, perlengkapan, alat - alat kerja dan alat bantu kerja; yang secara khusus digunakan di laboratorium, dalam rangka pelaksanaan pengujian, kalibrasi, dan produksi (dalam skala terbatas).

2. Bahan

Adalah segala sesuatu yang diolah/dipakai untuk pelaksanaan pengujian, kalibrasi, dan produksi (dalam skala terbatas) di dalam laboratorium.

3. Berdasarkan Metode Tertentu

Hal ini terkait dengan metode keilmuan yang dimiliki oleh pengguna laboratorium.

\section{Lembaga Keuangan Mikro Syariah}

Menurut UU no. 1 tahun 2013 pasal 1, Lembaga keuangan Mikro adalah lembaga keuangan yang khusus didirikan untuk memberikan jasa pengembangan usaha dan pemberdayaan masyarakat, baik melalui pinjaman atau pembiayaan dalam usaha skala mikro kepada anggota dan masyarakat, pengelolaan simpanan, maupun pemberian jasa konsultasi pengembangan usaha yang tidak semata-mata mencari keuntungan. Lembaga Keuangan Mikro Syariah terdiri dari berbagai lembaga diantaranya BPRS (Bank Pengkreditan Mikro Syariah), koperasi syariah, dan juga lembaga keuangan mikro syariah yang disebut Baitul Maal Wat Tamwil (BMT) yaitu lembaga keuangan mikro yang berbadan hukum koperasi syariah atau koperasi jasa keuangan syariah (KJKS). Ketiga lembaga tersebut mempunyai hubungan yang erat dengan lembaga syariah lainnya yang lebih besar. 
Esy Nur Aisyah: Mewujudkan Lembaga Keuangan Mikro Syariah

\section{METODE PENELITIAN}

Dalam penelitian ini, peneliti menggunakan pendekatan participatory yang sering disebut partisipatory action research (PAR). Pada dasarnya, PAR merupakan penelitian yang melibatkan secara aktif semua pihak-pihak yang relevan (stakeholders) dalam mengkaji tindakan yang sedang berlangsung (dimana pengalaman mereka sendiri sebagai persoalan) dalam rangka melakukan perubahan dan perbaikan ke arah yang lebih baik. Untuk itu, mereka harus melakukan refleksi kritis terhadap konteks sejarah, politik, budaya, ekonomi, geografis, dan konteks lain-lain terkait. Yang mendasari dilakukannya PAR adalah kebutuhan kita untuk mendapatkan perubahan yang diinginkan (Afandi, dkk, 2013).

\section{HASIL PENELITIAN}

\section{Rintisan Lembaga Keuangan Syariah berbasis Laboratorium}

El-Dinar Finance House merupakan laboratorium Perbakan Syariah Fakultas Ekonomi yang diresmikan pada hari Kamis,15 Jumadil Awal $1437 \mathrm{H}$ atau bertepatan pada tanggal 25 Februari 2016, yang diresmikan oleh Dekan Fakultas Ekonomi Bapak Dr. H. Salim Al-Idrus, MM., M.Ag di Aula Gedung Dr. (HC) Ir. Soekarno lantai 5 UIN Maulana Malik Ibrahim Malang .

Pendirian El-Dinar Finance House diprakarsai oleh para dosen Jurusan Perbankan Syariah (S1) diantaranya yaitu Dr. Siswanto, SE., M. Si, Anas Budiharjo, S.Hi.,CIFP, Yayuk Sri Rahayu, SE., MM, Putri Kurnia Widiati, SE., MM, Nihayatu Aslamatis S, SE., MM, Esy Nur Aisyah, SE., MM dan Ahmad Sidi Pratomo, S.Ei, M. A berdasarkan surat tugas Dekan Fakultas Ekonomi Nomor : Un.3.5/KP.01.4/689/2015 tentang Tim Pengembangan Transaksi Riil Mini Bank El Dinar di Fakultas Ekonomi UIN Maulana Malik Ibrahim Malang Tahun 2015 yang diketuai oleh ibu Yayuk Sri Rahayu, SE., MM.

Dengan adanya dukungan pimpinan Fakultas Ekonomi, dan dilatarbelakangi oleh masukan para mahasiswa Jurusan Perbankan Syariah (S1) untuk dapat melakukan praktikum di Labolatorium Perbankan, pihak Jurusan Perbankan Syariah (S1) merespon positif atas 
Esy Nur Aisyah: Mewujudkan Lembaga Keuangan Mikro Syariah

usulan tersebut dengan melakukan Riset Berbasis Kebijakan (Research Based Police) tentang revitalisasi peran labolatorium mini bank.

Hasil riset tersebut merekomendasikan dibentuknya lembaga mikro transaksi riil yang berfokus pada edukasi, serta merekomendasikan komunitas El-Dinar sebagai Motivator, Dinamisator, dan Inovator (MODIN) di El-Dinar Finance House.

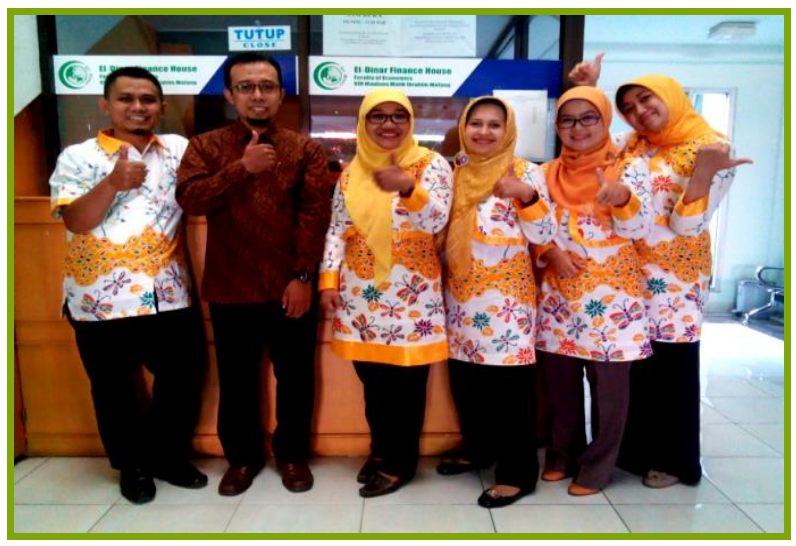

Gambar 1. Perintis El-Dinar Finance House

Tindak lanjut dari rekomendasi yang ada, para dosen Perbankan Syariah (S1) melakukan benchmark atau studi banding ke beberapa lembaga yang telah mengaplikasikan praktek laboratorium perbankan dengan sistem transaksi secara riil. Selang beberapa waktu ijtihad yang dilakukan dari hasil riset dan banchmark terbentuklah laboratorium mini bank yang diberi nama El-Dinar Finance House.

Setelah diresmikan, El-Dinar Finance House mulai beroperasi pada tanggal 29 Februari 2016, yang dioperasikan oleh 6 Supervisor dari pihak dosen Perbankan Syariah (S1), 26 Training of Trainers (ToT) ElDinar Finance House yang terdiri dari mahasiswa Perbankan Syariah S1, dan mahasiswa praktik yang menempuh mata kuliah Lab.Perbankan. Hingga saat ini, nasabah El-Dinar Finance House berasal dari dalam kampus UIN Maulana Malik Ibrahim Malang, yang terdiri dari pihak dosen, karyawan dan mahasiswa.

Pada awal pengoperasiannya, El-Dinar Finance House hanya memiliki satu produk dengan akad Wadi'ah berupa simpanan tabungan murni, namun seiring dengan pengembangan yang terus dilakukan, saat 
Esy Nur Aisyah: Mewujudkan Lembaga Keuangan Mikro Syariah

ini El-Dinar Finance House sudah melayani transaksi berupa tabungan Deposito Mudharabah, dan pembiayaan dengan akad Musyarakah. Selain itu El-Dinar Finance House juga menjalin kerjasama dengan BRI Syariah sebagai agen Laku Pandai untuk menjalankan transaksi PPOB.

\section{Motto, Visi, Misi, dan Layanan Laboratorium El-Dinar Finance House}

\section{Motto:}

"Unity in diversity"

\section{Visi}

Menjadi Pusat Pelatihan dan Pembelajaran Manajemen Lembaga Keuangan Mikro Syariah Berbasis Praktik.

\section{Misi}

1. Melaksanakan kegiatan pelatihan bagi mahasiswa dan stakeholders lainnya

2. Mendukung dan memfasilitasi pembelajaran berbasis praktik

3. Mengembangkan metode-metode pengelolaan manajemen lembaga keuangan mikro syariah (LKMS)

4. Menyebarluaskan (diseminasi) metode pengelolaan LKMS pada stakeholders

\section{Layanan dan Program Pelatihan}

1. Organisasi dan Manajemen laboratorium Keuangan Mikro Syariah

2. Manajemen Funding dan Financing

3. Manajemen Zakat dan Wakaf

4. Manajemen Keuangan LKMS

5. Manajemen Jasa LKMS

6. Manajemen Pemasaran Produk LKMS

7. Manajemen Risiko Pembiayaan

\section{Struktur Organisasi}

Adapun struktur organisasi di laboratorium El-Dinar Finance House adalah sebagai berikut: 


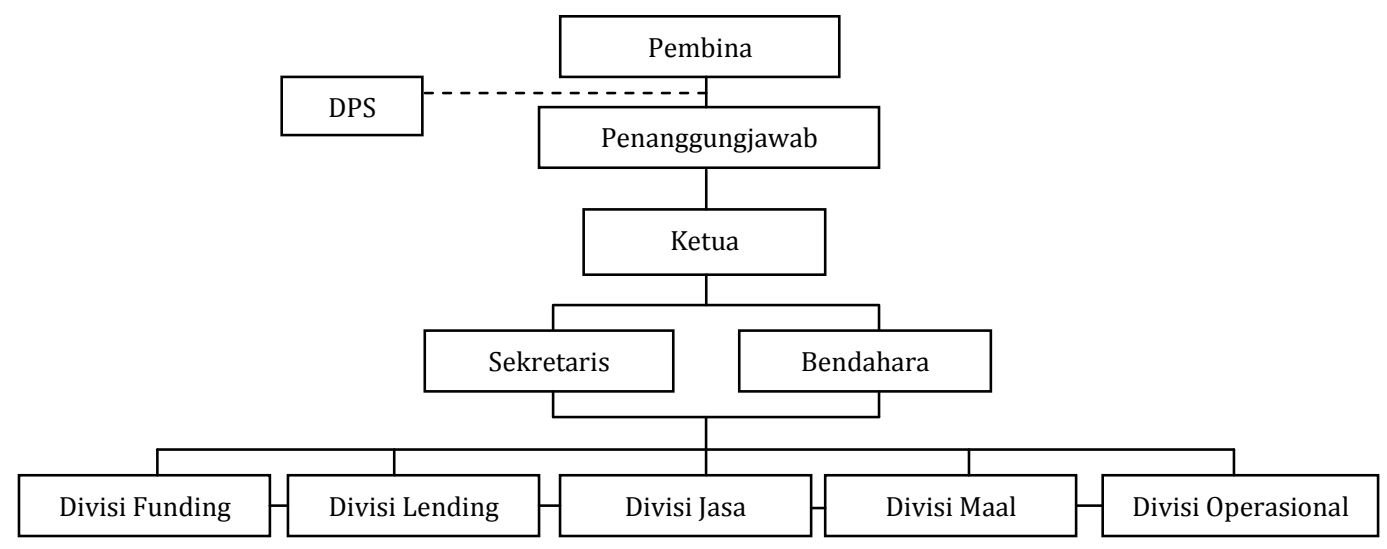

Gambar 2. Struktur Organisi El-Dinar Finance House

\section{Produk-produk El-Dinar Finance House}

El-Dinar Finance House memiliki beberapa produk dalam melayani nasabah yang ada di lingkungan UIN Maulana Malik Ibrahim Malang khususnya civitas akademika Fakultas Ekonomi.

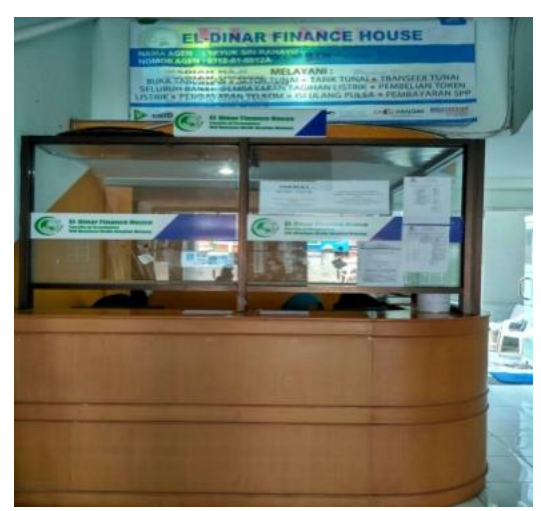

Gambar 3. Tempat Layanan el-Dinar Finance House

Adapun produk-produk layanan El-Dinar Finance House adalah sebagai berikut:

\section{Tabungan Wadi'ah}

\section{a) Definisi}

Yaitu produk simpanan yang menggunakan akad wadi'ah yad dhamanah.

b) Fitur

1) Gratis:

- Administrasi bulanan; 
Esy Nur Aisyah: Mewujudkan Lembaga Keuangan Mikro Syariah

- Setoran tunai;

- Pemindahbukuan Antar Tabungan Wadi'ah

2) Biaya Pembukaan Rekening; : : Rp. 5 Ribu

3) Minimal Setoran Awal : Rp 50 Ribu

4) Minimal Setoran Selanjutnya : Rp 1 Ribu

5) Saldo Minimal

: Rp.0,- atau Rp, 10,000

dengan ketentuan :

- $\quad$ Rp. 0 apabila saldo sudah dialihkan ke wakaf / infaq/shodaqoh

- $\quad$ Rp. 10,000 apabila saldo mengendap dapat diambil saat sudah lulus

6) Saldo Maksimal : Tidak dibatasi

7) Batas Maksimal Transaksi Debit (Transfer\&penarikan) : Tidak dibatasi (di atas Rp 500 Ribu harus konfirmasi)

8) Mendapatkan Bonus Tabungan setiap bulannya.

c) Persyaratan Umum

1) Warga Negara Indonesia.

2) Hanya untuk nasabah perorangan

3) Rekening tidak diperkenankan atas nama dua orang atau lebih

4) Belum memiliki CIF dan Rekening di El-Dinar Finance House

5) Memiliki kartu Identitas Asli (KTP) yang masih berlaku

6) Memiliki handphone dan SIM Card yang aktif yang akan digunakan sebagai nomor rekening nasabah.

d) Persyaratan Khusus

1) Mengisi formulir pembukaan rekening Tabungan Wadiah;

2) Menyerahkan foto copy KTP yang masih berlaku;

3) Mengisi form pernyataan pengalihan saldo minimal

4) Menyerahkan foto copy surat keterangan domisili yang dikeluarkan oleh desa/kelurahan/kecamatan (jika tempat pembukaan rekening tidak sesuai domisili).

\section{Deposito Mudharabah}

a) Definisi

Yaitu produk simpanan yang menggunakan akad Mudharabah Mutlaqoh.

b) Fitur
1) Nisbah bagi Hasil
: 60(nasabah) : 40(El-Dinar)
2) Tenur
: Bulanan dan Tahunan
3) Minimal Setoran
: Rp 50 Ribu 
Esy Nur Aisyah: Mewujudkan Lembaga Keuangan Mikro Syariah

c) Persyaratan Umum

1) Warga Negara Indonesia.

2) Hanya untuk nasabah perorangan

3) Memiliki rekening tabungan wadiah di El-Dinar Finance House

d) Persyaratan Khusus

1) Mengisi formulir pembukaan rekening Tabungan Mudharabah;

2) Menyerahkan foto copy Rekening Tabungan wadiah;

\section{Pembiayaan Musyarakah}

a) Definisi

Yaitu pembiayaan dengan menggunakan akad Musyarakah 'inan.

b) Fitur

1) Nisbah bagi Hasil $\quad: 50$ (nasabah) : 50 (El-Dinar).

2) Tenor : Bulanan dan Tahunan

3) Minimal Pembiayaan : Tidak dibatasi

4) Maksimal Pembiayaan : Menyesuaikan

5) Jaminan : : : Barang/ Garansi Perseorangan dan Ijazah SMA/SMK/MA

c) Persyaratan Umum

1) Warga Negara Indonesia.

2) Hanya untuk nasabah perorangan

3) Memiliki rekening tabungan wadiah di El-Dinar Finance House

4) Memiliki rekening tabungan deposito di El-Dinar Finance House.

d) Persyaratan Khusus

1) Mengajukan proposal pembiayaan

2) Mengisi formulir pengajuan pembiayaan

3) Foto copy rekening tabungan wadiah

4) Foto copy bukti setoran tabungan Deposito

5) Melampirkan Surat keterangan persetujuan orang tua

\section{Teman BRIS}

\section{a) Definisi}

Teman BRIS merupakan pihak ketiga yang berfungsi sebagai Agen Bank Syariah untuk menyediakan layanan perbankan kepada masyarakat. dalam hal ini El-Dinar Finance House menjadi Agen dari Bank Rakyat Indonesia Syariah (BRIS).

b) Program Layanan

Adapun yang dapat dilayani oleh teman BRIS adalah: 
Esy Nur Aisyah: Mewujudkan Lembaga Keuangan Mikro Syariah

1) Pembukaan rekening Tabungan Cerdas BRIS iB;

2) Informasi saldo Tabungan Cerdas BRIS iB;

3) Informasi Mutasi Rekening Tabungan Cerdas BRIS iB;

4) Setoran Tabungan Cerdas BRIS iB;

5) Tarik tunai tabungan Cerdas BRIS iB;

6) Transfer sesama tabungan Cerdas BRIS iB;

7) Transfer tabungan Cerdas BRIS iB ke tabungan Reguler BRISyariah.

\section{Tabungan Cerdas BRIS iB}

\section{a) Definisi}

Tabungan Cerdas BRIS iB merupakan produk tabungan dengan akad wadi'ah yang memiliki fitur yang cepat, murah, mudah dan dimana saja".

\section{b) Keunggulan}

1) Transaksi aman, karena:

- Setiap transaksi akan diminta konfirmasi password yang hanya diberikan ke nomor nasabah

- Setiap transaksi diinformasikan melalui sms kepada nasabah

2) Mudah diingat, karena no HP sebagai nomor rekening

3) Transaksi Keuangan Murah

4) Mendapatkan fasilitas Mobile Banking BRISSMART

5) Nyaman, karena dana yang tersimpan di rekening dijamin LPS

6) Tempat Transaksi Nasabah di seluruh Agen BRISyariah dan seluruh unit kerja BRISyariah.

7) Plus Bonus Tabungan setiap bulannya

\section{c) Fitur}

1) Gratis:

- Biaya Pembukaan Rekening;

- Administrasi bulanan;

- Setoran tunai;

- Pemindahbukuan Antar Tabungan Cerdas

- Transfer ke Tabungan Reguler BRISyariah.

2) Minimal Setoran Awal : Tidak dibatasi

3) Minimal Setoran Selanjutnya : Tidak dibatasi

4) Saldo Minimal : Rp.0,-

5) Saldo Maksimal : : Rp. 20 Juta 
Esy Nur Aisyah: Mewujudkan Lembaga Keuangan Mikro Syariah

6) Batas Maksimal Transaksi Debit (Transfer\&penarikan) :

Rp 5juta/bulan

7) Mendapatkan Bonus Tabungan setiap bulannya.

d) Persyaratan Umum

1) Warga Negara Indonesia.

2) Hanya untuk nasabah perorangan

3) Rekening tidak diperkenankan atas nama dua orang atau lebih

4) Belum memiliki CIF dan Rekening di BRISyariah

5) Memiliki kartu Identitas Asli (KTP) yang masih berlaku

6) Memiliki handphone dan SIM Card yang aktif yang akan digunakan sebagai nomor rekening nasabah.

\section{e) Persyaratan Khusus}

1) Mengisi formulir pembukaan rekening Tabungan Cerdas BRISyariah iB.

2) Menyerahkan foto copy KTP yang masih berlaku

3) Menyerahkan foto copy surat keterangan domisili yang dikeluarkan oleh desa/kelurahan/kecamatan (jika tempat pembukaan rekening tidak sesuai domisili).

\section{PPOB (Payment Point Online Bank)}

El-Dinar Finance House bekerjasama dengan BRISyari'ah sebagai agen Laku Pandai menggunakan akad Wakalah, menyediakan beberapa fasilitas yaitu diantaranya :

a) Pembiayaan tagihan listrik

b) Pembayaran telephon/hp

1) Telkom (Telephon Rumah dan Telkom Fleksi)

2) Telkomsel,XL,Esia, dan Smartfren

c) Pembayaran internet (Telkom,speedy)

d) TV berbayar (TelkomVision)

e) Pembayaran biaya pendidikan

f) Donasi

g) Pembelian : Token Listrik dan Pulsa minimal Rp, 20.000 (telkomsel,XL,Esia,Indosat, dan smartfren)

\section{ZISWAF}

Meliputi Pengumpulan dan penyaluran dana zakat, infaq, shadaqoh, dan wakaf. 
Esy Nur Aisyah: Mewujudkan Lembaga Keuangan Mikro Syariah

\section{Training of Trainer El-Dinar Finance House}

Training of Trainer laboratorium El-Dinar Finance House atau biasa dikenal dengan sebutan ToT adalah sebuah komunitas di bawah jurusan Perbankan Syariah S1. Pada awalnya laboratorium ini dibina oleh Bapak Anas Budiharjo S.Hi.,CIFP dan Ibu Putri Kurnia Widiati SE,. MM dengan sebuah produk tabungan Wadi'ah. Saat ini El-Dinar dibina oleh Ibu Esy Nur Aisyah SE.,.MM dengan jumlah ToT sebanyak 26 orang.

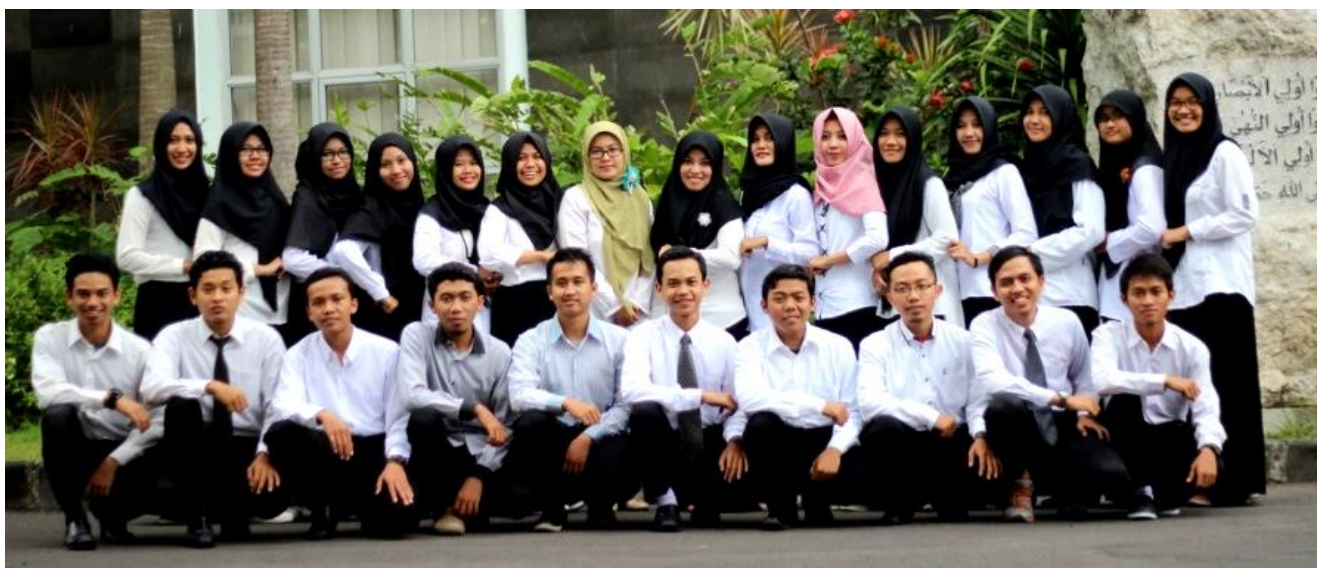

Gambar 4. ToT El-Dinar Finance House

Kegiatan yang dilakukan ToT diantaranya:

1. Kegiatan Utama ToT

Adalah menjalankan transaksi riil seperti setoran, penarikan, pembukaan rekening, dari opening hingga closing dan bertugas sebagai Teller dan Customer Service. El-Dinar Finance House buka setiap hari Senin sampai Jum'at mulai pukul 09.30 sampai pukul 13.30. Saat ini El-Dinar memiliki beberapa produk seperti : tabungan wadiah, deposito mudharabah, pembiayaan musyarakah, PPOB, Laku Pandai BRIS, dan ZISWAF.

2. Kegiatan lainnya:

a. Menyusun SOP (Standar Operasional Prosedur), pengembangan produk dan menyusun laporan keuangan.

b. Pelatihan, Rapat Koordinasi Bulanan dan Kajian ToT pada minggu ketiga setiap bulan.

c. Melakukan Training Mahasiswa Praktik Perbankan Syariah (S1) yang sedang menempuh mata kuliah Laboratorium Perbankan Syariah. 
Esy Nur Aisyah: Mewujudkan Lembaga Keuangan Mikro Syariah

\section{PEMBAHASAN}

Mendirikan Laboratorium bank syariah hampir sama dengan mendirikan KJKS (Koperasi Jasa Keuangan Syariah) ataupun BPRS (Bank Pembiayaan Rakyat Syariah). Pertama kali yang perlu dipikirkan adalah pilihan badan hukum. Jika diinginkan memilih badan hukum usaha yang pertama, tentu konsekuensi logis yang mengacu kepada peraturan menteri Negara koperasi dan usaha kecil, maka peran Koperasi hanya sebagai intermediasi dari anggota kepada anggota dalam penerimaan simpanan dan alokasi pembiayaan. Laboratorium tidak diperkenankan investasi langsung sebagaimana substansi dari keuangan Islam. Begitupun jika yang diinginkan adalah yang kedua, maka akan mengikuti peraturan Otoritas Jasa Keuangan.

Operasional atau layanan laboratorium perbankan syariah mengacu pada matakuliah yang ditempuh mahasiswa. Pemahaman yang diperoleh mahasiswa dapat mempermudah mereka dalam menjelaskan karakteristik bank syariah. Bagaimana membuat laporan keuangan syariah, dan menghitung bagi hasil yang biasanya dibagikan setiap bulan kepada anggota (atau dalam bank dikatakan sebagai nasabah), dengan penggunaan software sederhana yaitu microsoft excel. Dengan demikian, Fakultas Ekonomi dapat merancang kurikulum yang mampu menjawab peluang dan tantangan di atas. Perlu adanya rancangan kurikulum berbasis kompetensi serta berbagai metode pembelajaran perlu diimplementasikan seperti misal: Project Based Learning (PBL), Problem Solving, Role playing, Simulasi ataupun praktek secara riil (Johnson,2007).

Adanya hasil manajemen dana, tidak terlepas dari upaya pengelola laboratorium untuk dapat mengelola pembiayaan. Beberapa jenis keuntungan yang bisa diterapkan yaitu prinsip margin (murabahah), ujrah, dan bagi hasil. Akad pembiayaan yang dapat dipraktekkan adalah pembiayaan mudharabah, musyarakah, murabahah, salam, ishtishna dan Qard. Selain berorientsasi pada laba, laboratorium perbankan syariah bisa menjadi amil atas kegiatan maal (dana sosial). Mengelola dana-dana filantropi islam yaitu dana Zakat, Infaq, Sedekah, dan Wakaf.

Agar Laboratorium perbankan syariah dapat dijalankan dengan baik dan benar, maka diperlukan terlebih dahulu penyusunan SOP (Standar Operasional Prosedur). SOP disini terdiri dari SOP Transkasi Harian (opening - closing), SOP Tabungan (pembukaan, setoran, penarikan, penggantian buku, pencairan, dan penutupan), SOP Pembiayaan (pengajuan, survey/analisa pembiayaan, 
Esy Nur Aisyah: Mewujudkan Lembaga Keuangan Mikro Syariah

persetujuan/realisasi pembiayaan, setoran angsuran dan pelunasan), SOP jasa (transaksi PBOB), dan SOP Dana Sosial (pengumpulan dana ZISWAf, dan distribusi dana Ziswaf).

\section{PENUTUP}

Laboratorium Bank Syariah merupakan sarana penopang pelaksanaan program Tri Dharma Perguruan Tinggi yang diharapkan mampu memberikan kontribusi turut mengakselerasi perkembangan syariah di Indonesia, maupun dapat berfungsi sebagai unit produksi Prodi ataupun Fakultas Ekonomi. Peran Laboratorium riil menjadi sangat penting untuk djadikan sumber pembelajaran bank syariah sekaligus media sosialisasi atau edukasi dalam lingkup civitas akademika. Hasil dari pelaksanaan praktek di Laboratorium transaksi riil, demikian pula intensitas transaksi yang bakal berlangsung sangat ditentukan oleh oleh beberapa hal seperti: dukungan kebijakan pimpinan institusi khususnya dalam lingkup prodi dan Fakultas. Kebijakan dalam penyusunan kurikulum yang mendukung pelaksanaan praktek sangat menentukan, dan tak kalah pentingnya adalah sistem dan model pembelajaran yang diberlakukan.

\section{DAFTAR PUSTAKA}

Afandi, Agus, dkk, 2013. Modul Participatory Action Reseacrh (PAR). Surabaya: Lembaga Pengabdian Masyarakat (LPM) IAIN Sunan Ampel.

Ascarya dan Yusmanita D, 2008. Comparing The Efficiency Islamic Banks in Malaysia and Indonesia. Buletin Ekonomi \& Moneter Bank Indonesia, Vol. 11, No. 2.

Johnson, E., B. 2007. "Contextual Teaching and Learning: Menjadikan Kegiatan Belajar-Mengajar Mengasyikan dan Bermakna". Terjemahan: Ibnu Setiawan. MLC. Bandung.

Hamzah, M. 2008. Pengembangan Perbankan Syariah Secara Obyektif dan Rasional Dengan Pendekatan Mekanisme Pasar. Jurnal Ekonomi Islam: La Riba, Vol. 2., No. 1.

Zuhro, Idah, 2012. Penguatan Laboratorium Bank Syariah Untuk Mendukung Perkembangan Industri Keuangan Syariah. Ekonomika-Bisnis Vol. 03 No.1 Bulan Januari Tahun 2012. Hal 1328. 